\title{
Over-the-counter Drug Induced Autoimmune Hepatitis
}

\author{
Karin Takeda ${ }^{1}$, Masaya Oda ${ }^{2}$, Takemichi Okada ${ }^{3}$, Hitoshi Yamazaki ${ }^{4}$, \\ Makoto Ohbu ${ }^{5}$, Masaaki Watanabe ${ }^{1}$ and Hiroaki Yokomori ${ }^{1}$
}

\begin{abstract}
A 64-year-old man seeking treatment for a common cold was admitted to our hospital due to symptoms of general fatigue and liver dysfunction. A thorough history review revealed that the patient had recently started taking an over-the-counter (OTC) drug. Drug-induced lymphocyte stimulation tests were positive. Serum markers for autoimmune hepatitis (AIH) were particularly elevated. Liver biopsy revealed spotty necrosis and ceroid-pigmented Kupffer cells and piecemeal necrosis with multiple plasma cells. He responded to corticosteroids, thus suggesting the presence of an immune-mediated component associated with the liver injury. Liver injury after using OTCs should be included in the differential diagnosis for chronic hepatitis with features of AIH.
\end{abstract}

Key words: drug-induced hepatic injury, autoimmune hepatitis, over-the-counter drug, immunohistochemistry, electron microscopy

(Intern Med 55: 1293-1297, 2016)

(DOI: 10.2169/internalmedicine.55.5509)

\section{Introduction}

Drug-induced liver injury (DILI) is being increasingly recognized as a cause of clinically significant acute and chronic liver disease. Marked geographic variation exists among the agents responsible for causing DILI (1). In fact, DILI is associated with certain over-the-counter (OTC) drugs, prescription drugs, and dietary supplements, many of which make bold promises about improving symptoms and bolstering health (2). A popular Japanese cold medicine Pabron Gold ${ }^{\mathbb{B}}$ (Taisho Pharma, Tokyo, Japan) can be purchased at pharmacies in Japan, Thailand, Malaysia, and Chinese Taipei as a multi-component cold medicine.

Autoimmune hepatitis (AIH) is pathologically characterized by chronic necro-inflammation, manifested as severe lobular necrosis and inflammation with broad areas of parenchymal collapse with no known cause. The etiology of AIH remains uncertain, but external factors such as viruses, drugs, or herbal remedies can sometimes trigger this disease in susceptible persons (3). Recently, drug-induced AIH (DIAIH) has come to account for a sizable share, approximately
9\%, of all AIH cases (4). This report is the first to describe a patient who developed DI-AIH following the use of an OTC drug. This case is characterized by cholestasis and the histologic features of AIH which improved after the administration of corticosteroid therapy.

\section{Case Report}

A 64-year-old man seeking treatment for a common cold was admitted to our hospital for general fatigue and liver dysfunction. He had not reported any liver dysfunction. Blood test results included data for total bilirubin (T-bil) 2.4 $\mathrm{mg} / \mathrm{dL}$; direct bilirubin (D-bil) $1.4 \mathrm{mg} / \mathrm{dL}$; aspartate aminotransferase (AST) 1,244 IU/L; alanine aminotransferase (ALT) 1,455 IU/L; alkaline phosphatase (ALP) 1,242 IU/L; and $\gamma$-glutamyl transpeptidase $(\gamma$-GTP) 599 IU/L. Viral hepatitis serology was negative. Other relevant data included an immunoglobulin (Ig) $\mathrm{G}$ concentration of $1,907 \mathrm{mg} / \mathrm{dL}$, IgM of $95 \mathrm{mg} / \mathrm{dL}$, anti-nuclear antibody (ANA) $\times 80$ (cut-off $<\times 40$ ), anti-smooth muscle antibody (ASMA) $\times 20$ (cut-off $<\times 20$ ), negative liver kidney microsomal type 1 (LKM-1) (cut-off <5.0), and negative mitochondria M2Ab (cut-off

\footnotetext{
${ }^{1}$ Department of Internal Medicine, Kitasato University Medical Center, Japan, ${ }^{2}$ Organized Center of Clinical Medicine, International University of Health and Welfare, Japan, ${ }^{3}$ Department of Radiology, Kitasato University Medical Center, Japan, ${ }^{4}$ Division of Pathology, Kitasato University Medical Center, Japan and ${ }^{5}$ Department of Pathology, School of Allied Health Sciences, Kitasato University, Japan

Received for publication April 7, 2015; Accepted for publication June 22, 2015

Correspondence to Dr. Hiroaki Yokomori, yokomori@insti.kitasato-u.ac.jp
} 
Table. Laboratory Data.

\begin{tabular}{|c|c|c|c|c|c|}
\hline \multicolumn{3}{|l|}{ (Blood count) } & \multicolumn{3}{|l|}{ (Serological examination) } \\
\hline White blood cell & 9,900 & $3,300-9,000 / \mu \mathrm{L}$ & IgM-hepatitis A virus antibody & $(-)$ & $(-)$ \\
\hline (Neutrocyte 64\%, & & & Hepatitis B surface antigen & $(-)$ & $(-)$ \\
\hline Lymphocyte $24.1 \%$, & & & IgM-hepatitis B core antibody & $(-)$ & $(-)$ \\
\hline Monocyte10.2\%, & & & $\mathrm{Ab}$, hepatitis $\mathrm{C}$ virus antibody & $(-)$ & $(-)$ \\
\hline Eosinocyte $0.6 \%$ ) & & & Hepatitis C virus - RNA & $<1.2$ & $<1.2 \log \mathrm{IU} / \mathrm{mL}$ \\
\hline Red blood cell count & $485 \times 10^{4}$ & $380-500 \times 10^{4} / \mu \mathrm{L}$ & IgM-cytomegalovirus & $<10$ & $(-)$ \\
\hline Hemoglobin & 15.4 & $11.5-15.0 \mathrm{~g} / \mathrm{dL}$ & IgM-Epstein-Barr virus-viral & $\times 10$ & $<\times 10$ \\
\hline \multirow[t]{2}{*}{ Platelet } & $239 \times 10^{3}$ & $140-340 \times 10^{3} / \mu \mathrm{L}$ & capsid antigen antibody & & \\
\hline & & & $\begin{array}{l}\text { IgG-Epstein-Barr virus-viral } \\
\text { capsid antigen antibody }\end{array}$ & $\times 80$ & $<\times 10$ \\
\hline \multirow[t]{2}{*}{ (Coagulation system) } & & & $\begin{array}{l}\text { IgG-Epstein-Barr virus-nuclear } \\
\text { antigen antibody }\end{array}$ & $\times 20$ & $<\times 10$ \\
\hline & & & Hepatitis E virus antibody & $(-)$ & $(-)$ \\
\hline International normalized ratio & 0.98 & $0.85-1.15$ & IgM-herpes simplex virus & $<0.80$ & $<0.80$ \\
\hline \multirow{3}{*}{ of prothrombin time } & & & Immunoglobulin $\mathrm{G}$ & 1,907 & $870-1,700 \mathrm{mg} / \mathrm{dL}$ \\
\hline & & & Immunoglobulin $\mathrm{M}$ & 95 & $46-260 \mathrm{mg} / \mathrm{dL}$ \\
\hline & & & Anti-nuclear antibody & $\times 80$ & $<\times 40$ \\
\hline \multirow[t]{2}{*}{ (Blood chemistry) } & & & Anti-mitochondrial $\mathrm{M} 2$ antibody & $<5.0$ & $<5.0$ \\
\hline & & & Anti-smooth muscle antibody & $\times 20$ & $<\times 20$ \\
\hline Total bilirubin & 2.4 & $0.2-1.2 \mathrm{mg} / \mathrm{dL}$ & & & \\
\hline Direct bilirubin & 1.4 & $0.0-0.2 \mathrm{mg} / \mathrm{dL}$ & & & \\
\hline Aspartate aminotransferase & 1,244 & 10-40IU/L & \multirow{2}{*}{\multicolumn{2}{|c|}{ (Drug-induced lymphocyte stimulation test) }} & \\
\hline Alanine aminotransferase & 1,455 & $5-45 \mathrm{IU} / \mathrm{L}$ & & & \\
\hline Lactate dehydrogenase & 666 & $120-240 \mathrm{IU} / \mathrm{L}$ & \multirow[t]{3}{*}{ Pabron gold $\AA$ : $2447 \mathrm{cpm}(503 \%)$} & & $<179 \%$ \\
\hline Alkaline phosphatase & 1,242 & $100-325 \mathrm{IU} / \mathrm{L}$ & & & \\
\hline$\gamma$-glutamyl transpeptidase & 598 & $<30 \mathrm{IU} / \mathrm{L}$ & & & \\
\hline Choline esterase & 321 & $234-493 \mathrm{IU} / \mathrm{mL}$ & \multicolumn{2}{|c|}{ (Human leukocyte antigen DR study) } & \\
\hline Total protein & 7.6 & $6.5-8.1 \mathrm{~g} / \mathrm{dL}$ & & & \\
\hline Albumin & 4.3 & $3.8-5.3 \mathrm{~g} / \mathrm{dL}$ & \multicolumn{2}{|l|}{ DRB*1-0405 (DR4) } & \\
\hline Total cholesterol & 189 & $120-219 \mathrm{mg} / \mathrm{dL}$ & & & \\
\hline Triglyceride & 87 & $30-149 \mathrm{mg} / \mathrm{dL}$ & & & \\
\hline Blood urea nitrogen & 9.2 & $8.0-22 \mathrm{mg} / \mathrm{dL}$ & & & \\
\hline Creatinine & 0.84 & $0.60-1.10 \mathrm{mg} / \mathrm{dL}$ & & & \\
\hline C-reactive protein & 0.46 & $<0.3 \mathrm{mg} / \mathrm{dL}$ & & & \\
\hline Glucose & 99 & $70-109 \mathrm{mg} / \mathrm{dL}$ & & & \\
\hline Hemoglobin A1c & 6.0 & $4.3-5.8 \%$ & & & \\
\hline
\end{tabular}
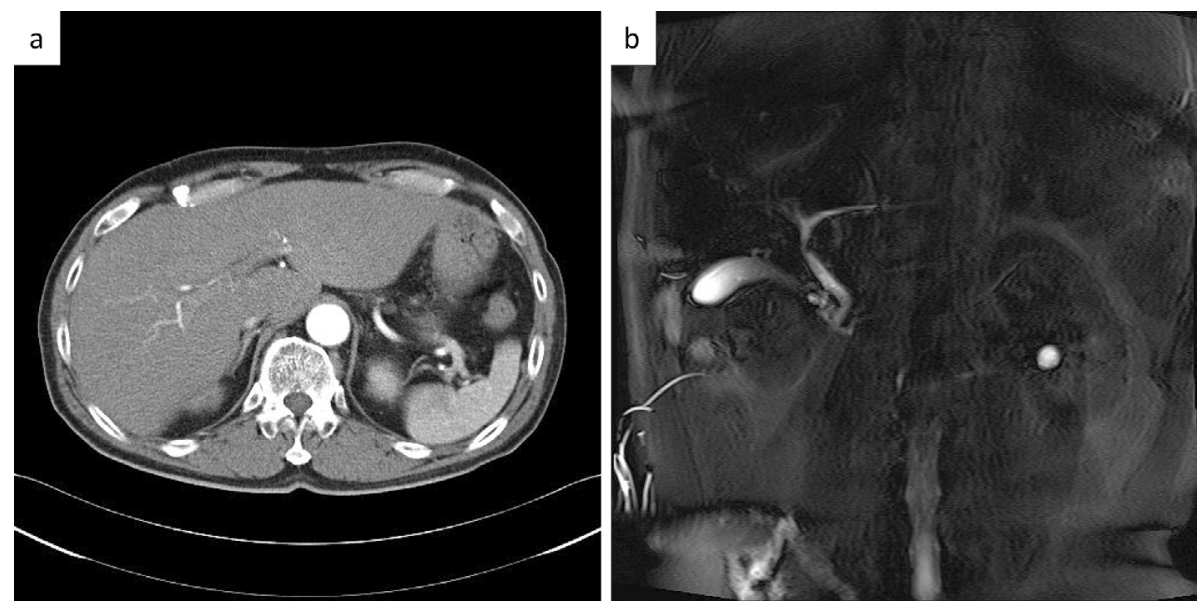

Figure 1. Radiographic findings. a: Computed tomography (axial image, arterial phase) imaging showed no mass lesions. b: Magnetic resonance cholangiopancreatography (MRCP) showed no stones in the common bile duct and no extrahepatic biliary duct dilatation.

$<5.0)$ (Table). Computed tomography revealed no sign of any mass lesions (Fig. 1a). Magnetic resonance cholangiopancreatography revealed no stones or extrahepatic biliary duct dilatation (Fig. 1b). A review of the patient history revealed that he had been self-administering an OTC drug, Pabron Gold $^{\circledR}$ (each tablet containing $8 \mathrm{mg}$ dihydrocodeine phosphate, $20 \mathrm{mg}$ di-methylephedrine hydrochloride, 41.67 $\mathrm{mg}$ guaifenesin, $300 \mathrm{mg}$ acetaminophen, $20 \mathrm{mg}$ lysozyme hydrochloride, $2.5 \mathrm{mg}$ carbinoxamine maleate, $25 \mathrm{mg}$ anhydrous caffeine, $8 \mathrm{mg}$ bisibutiamine, and $4 \mathrm{mg}$ riboflavin) for upper respiratory inflammation. He had taken three tablets daily for 3-4 day periods three times during the prior three 

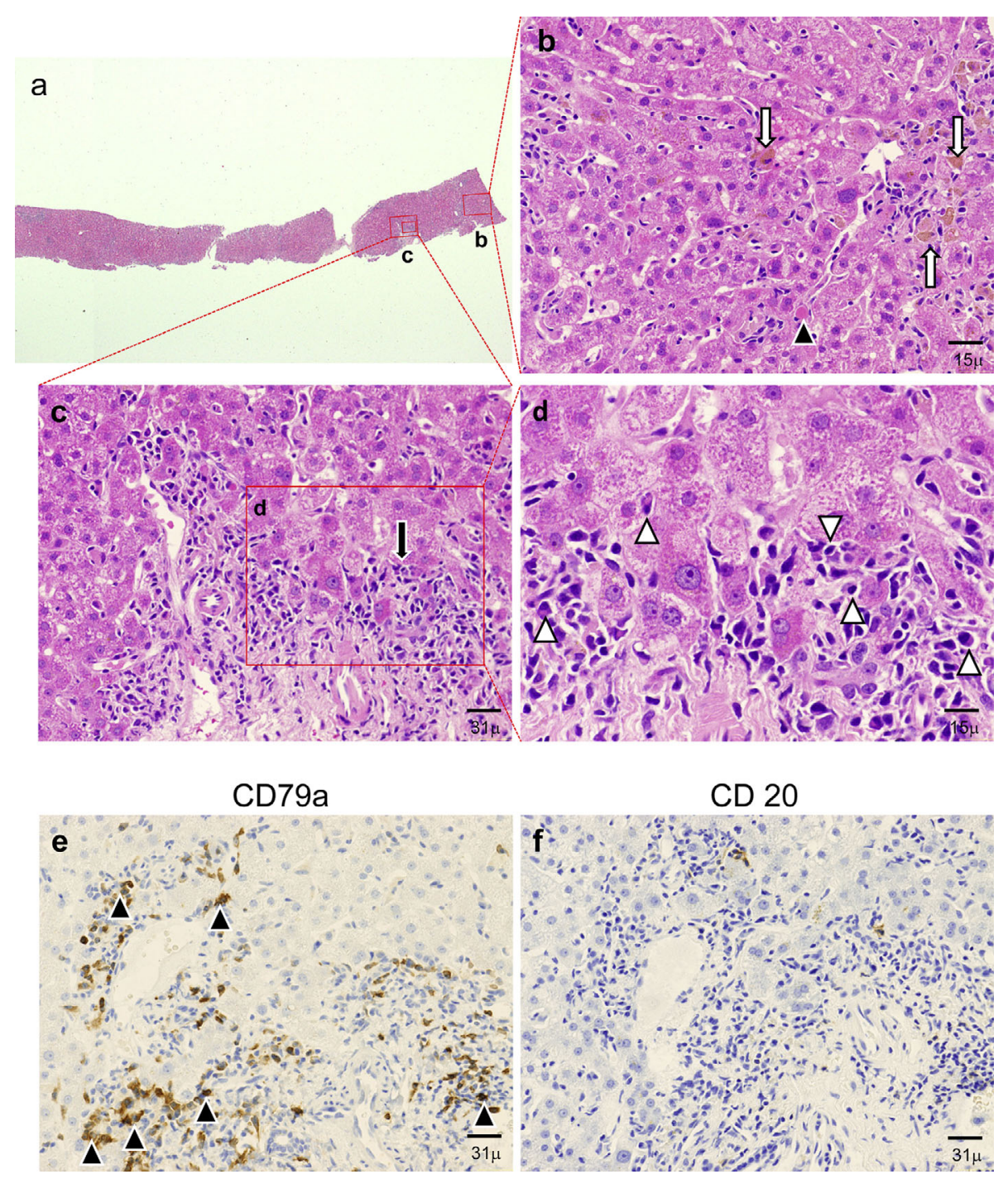

Figure 2. Light microscopy of liver biopsy. a: Low-magnification view $(\times 3.5)$ showing prominent portal inflammation distributed evenly throughout the portal tracts with mononuclear inflammation. b: High power view of a, square b. The black arrowhead indicates single cell necrosis. Ceroidpigmented Kupffer cells around the central vein (white arrows). c: Moderate (c) and high-power (d) view of a, square c. Moderate portal inflammation infiltrated with interface hepatitis (white arrowheads) by lymphocytes and plasma cells (white arrowheads) around the portal tracts. The black arrowhead indicates spotty necrosis. The black arrow indicates interface hepatitis. e, f: Results of immunohistochemical analyses of CD79a and CD20 markers. The arrowheads indicate plasma cells, which are positive for CD79a (e), but negative for CD20 (f).

months. Thereafter, he started to develop persistent epigastric distress and general malaise. His symptoms worsened whenever he took that medication. He was referred to our hospital two days after the last dose. After one month of Pabron Gold ${ }^{\circledR}$ treatment, the patient started to develop persistent general malaise. The cause was suspected to be liver injury. A DI lymphocyte stimulation test for Pabron Gold ${ }^{\mathbb{R}}$ was positive: $2,447 \mathrm{cpm}(503 \%)(<179 \%)$. A needle liver biopsy was performed on admission day 3, the results of which revealed spotty necrosis and ceroid-pigmented Kupffer cells around the central vein (Fig. 2a and b) and interface hepatitis with multiple plasma cells around the portal tracts (Fig. 2a, c, d). Plasmocytic infiltration showed positive CD79a staining with negative CD20 staining
(Fig. 2e and f). These infiltrated cells were found to be plasma cells by immunohistochemistry. Ultrastructurally, a "cart-wheel" chromatin configuration in the nucleus was observed in some plasma cells packed with many roughsurfaced endoplasmic reticulum (Fig. 3a and b). Moreover, characteristic granular osmiophilic materials and lipid droplets were observed in the Kupffer cells (Fig. 3c and d). The human leukocyte antigen (HLA) typing test was HLA-DRB *1-0405 (DR4) positive. The use of Pabron Gold ${ }^{R}$ was strongly suspected as being responsible for the patient's condition. The DI hepatitis score (5) was 8, AIH diagnosis (6) was 6: probable. Liver function improvement was noted after administering a liver protection agent: glycyrrhetinic acid. 

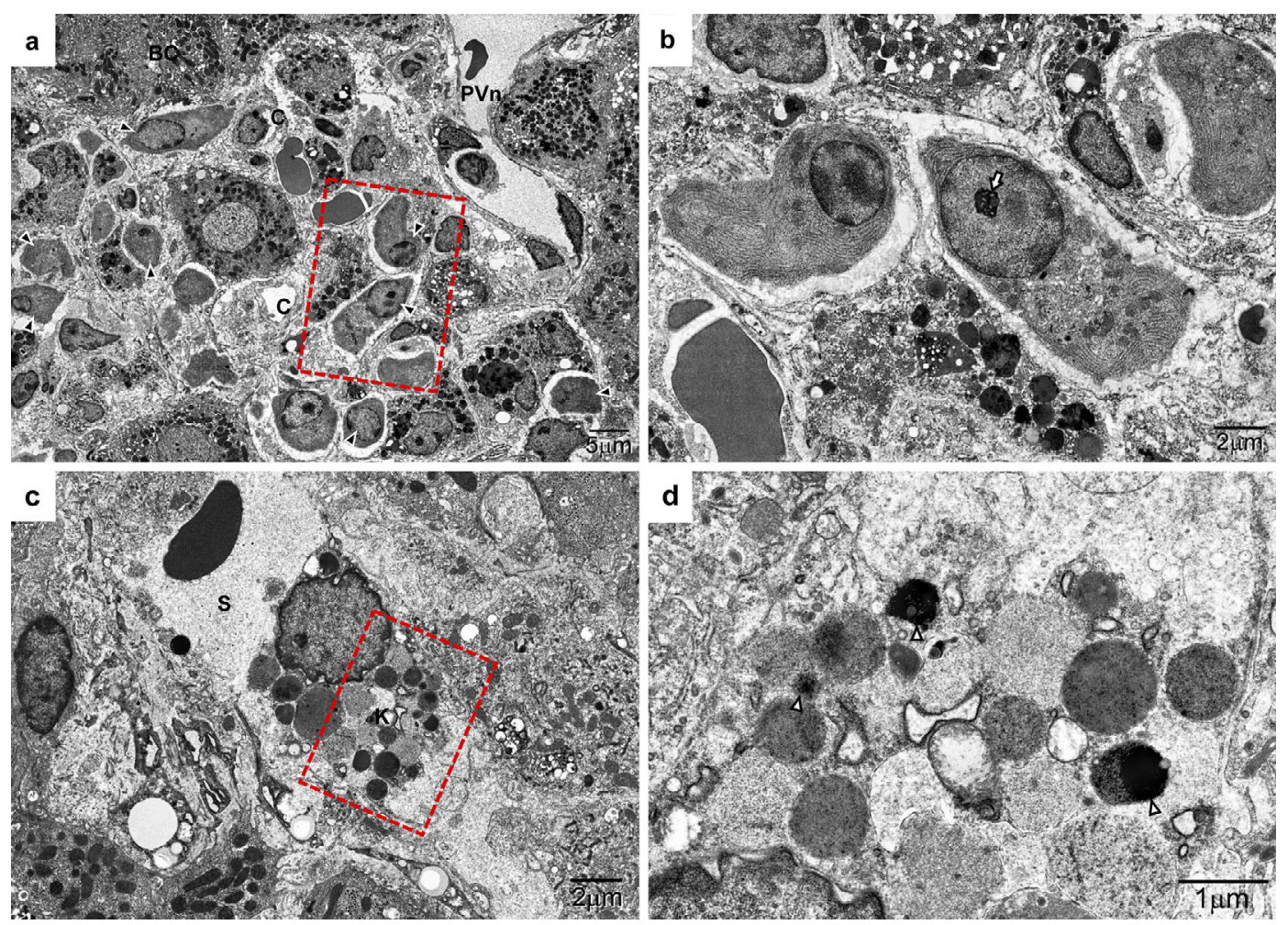

Figure 3. Electron microscopy. a, b: Plasma cells were filled with markedly rough endoplasmic reticulum in the electron microscope findings. Some of these cells exhibited a "wheel" chromatin structure of the nucleus in a portal field with chronic inflammatory cells. c, d: Hepatic sinusoid (s) showing lumen containing sinusoidal endothelial cells and Kupffer cells containing densely staining material around the central vein. Characteristic granular and osmiophilic electron dense structures and lipid droplets are shown. a, c: low magnification, b, d: high magnification. Scale bars show $5 \mu \mathrm{m}$ or 2 or $1 \mu \mathrm{m}$. The arrowheads indicate plasma cells, density staining materials. The white arrow indicates a "cartwheel" chromatin configuration. The white arrowhead indicates granular and osmiophilic electron dense structure. Pvn denotes portal venule. c denotes capillary artery or arteriole. BC denotes bile canaliculus. $\mathrm{K}$ denotes Kupffer cell. $\mathrm{S}$ denotes hepatic sinusoid.

He showed a persistent rise in the transaminase concentrations at around day 30. Therefore, steroids with prednisolone were prescribed at a dose of $40 \mathrm{mg} /$ day to control the hepatic inflammation contributing to the hepatocellular injury. The transaminase levels began to decline after the administration of prednisolone for 3 days. They thereafter normalized by the end of two weeks (Fig. 4).

\section{Discussion}

This report is the first to describe a case of DI-AIH following the use of an OTC drug. In fact, a DI-AIH diagnosis presents a challenge to clinicians because neither the histological nor clinical pathognomonic features of AIH have yet been elucidated. Moreover, HLA haplotypes do not convincingly distinguish these two entities (4). It is practically impossible to exclude potential drug involvement in some cases. Therefore, making a differential diagnosis of idiopathic AIH or DI-AIH can be extremely difficult. Clinically, DI-AIH commonly has an acute onset and a low frequency of cirrhosis at presentation and during follow-up (4).

In all, $14 \%$ of such cases exhibit clinically severe hepato- cellular injury and jaundice on either initial or rechallenge events. Most patients (52\%) undergo drug rechallenge within a month following the initial liver injury event (7).

During follow-up, regarding transferases with the liver protection agent, our patient showed a persistent increase in the transaminase levels, elevated immunoglobulin levels, and ASMA values, which were monitored in spite of plasma cell infiltration observed from liver histology because of the inferred DI-AIH related liver damage (8). Suspecting DI-AIH, in accordance with the data and recommendations reported to date and because treatment should be initiated as soon as possible, we initiated prednisolone treatment at an early stage (4).

Liver biopsy revealed the prominence of ceroid pigment within Kupffer cells in the centrilobular areas. The laboratory data and liver biopsy findings suggested hepatitis with cholestatic features (9). Kupffer cells are highly phagocytic members of the mononuclear phagocyte family. In response to hepatocyte damage from OTC intake, they can proliferate and enlarge, often amassing a so-called ceroid pigment, a material that chemically resembles lipofuscin, which is derived from phagocytosed cellular debris (10). Ceroid pig- 


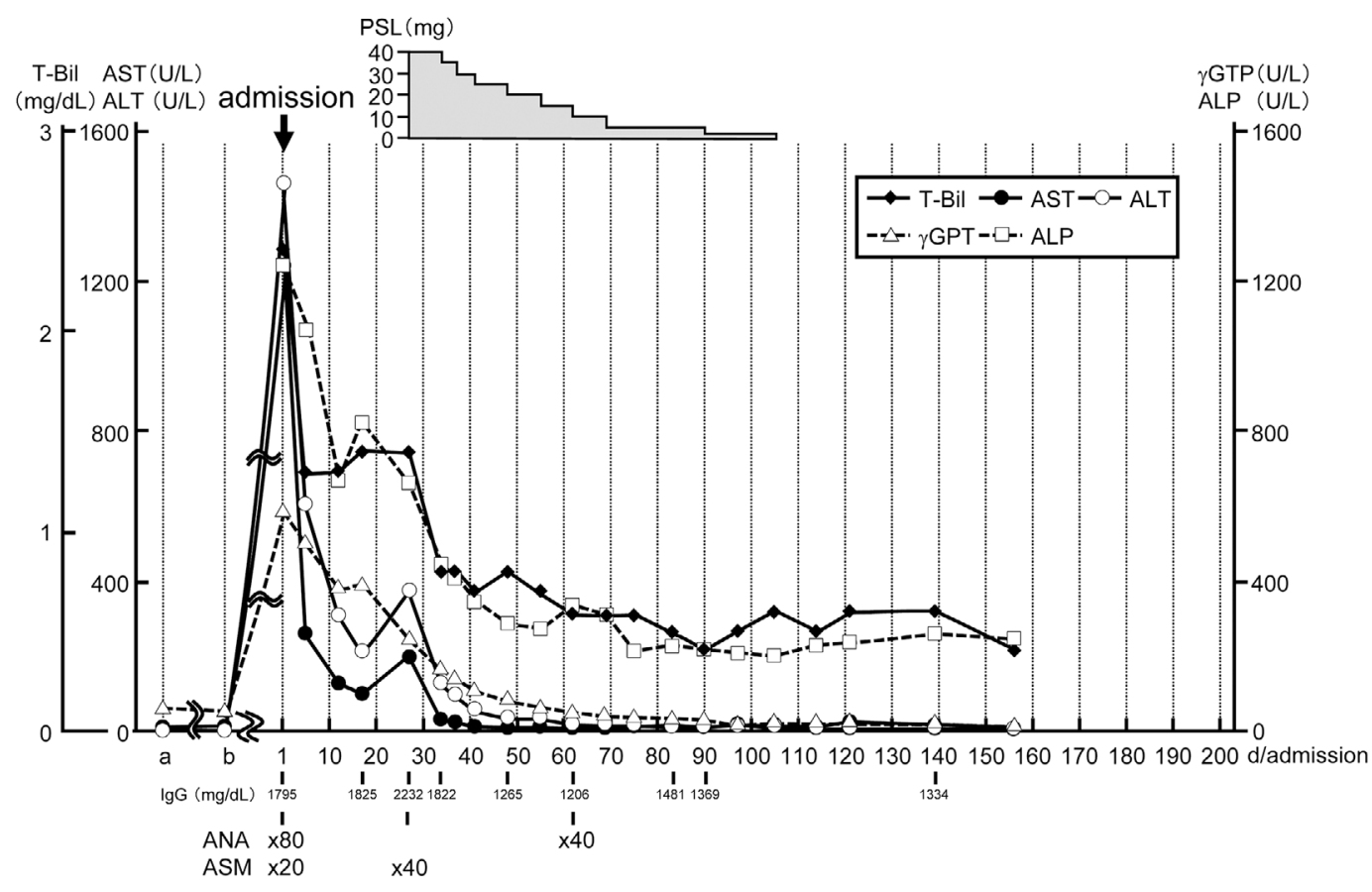

Figure 4. Clinical course. T-Bil: total bilirubin, AST: aspartate aminotransferase, ALT: alanine aminotransferase, ALP: alkaline phosphatase, $\gamma$-GTP: $\gamma$-glutamyl transpeptidase. a, b: day of regular medical examination. a: three years prior. b: one year prior.

ments are apparent in acute viral hepatitis, acute $\mathrm{AIH}$, and an acute exacerbation of AIH other than DILI. Therefore, this finding is not pathognomonic for DILI. Rather, it shows the presence of acute hepatocellular injury (11). Consequently, it is difficult to differentiate DIHI acute $\mathrm{AIH}$, or an acute exacerbation of AIH using histology alone.

In this case, the plasmocytic cells in the periportal areas were positive for CD79a, but they were negative for CD20 (Fig. 3e and f). In fact, these results resembled the previously reported results in the literature (12). Numerous plasma cells infiltrating the periportal area were observed from liver histology. In conclusion, this case of OTC drug Pabron Gold ${ }^{\mathbb{R}}$-associated liver injury, diagnosed as DI-AIH, underscores the need for caution in the use of OTC drugs.

Written informed consent was obtained from the patient for publication of this case report and any accompanying images.

The authors state that they have no Conflict of Interest (COI).

\section{References}

1. Fontana RJ, Seeff LB, Andrade RJ, et al. Standardization of nomenclature and causality assessment in drug-induced liver injury: summary of a clinical research workshop. Hepatology 52: 730$742,2010$.
2. Chalasani NP, Hayashi PH, Bonkovsky HL, et al; Practice Parameters Committee of the American College of Gastroenterology. ACG Clinical Guideline: The diagnosis and management of idiosyncratic drug-induced liver injury. Am J Gastroenterol 109: 950966, 2014.

3. Krawitt EL. Autoimmune hepatitis. N Engl J Med 354: 54-66, 2006.

4. Czaja AJ. Drug-induced autoimmune-like hepatitis. Dig Dis Sci 56: 958-976, 2011.

5. Takikawa H, Takamori Y, Kumagai T, et al. Assessment of 287 Japanese cases of drug induced liver injury by the diagnostic scale of the International Consensus Meeting. Hepatol Res 27: 192-195, 2003.

6. Hennes EM, Zeniya M, Czaja AJ, et al. Simplified criteria for the diagnosis of autoimmune hepatitis. Hepatology 48: 169-176, 2008.

7. Papay JI, Clines D, Rafi R, et al. Drug-induced liver injury following positive drug rechallenge. Regul Toxicol Pharmacol 54: 84-90, 2009.

8. Sugimoto K, Ito T, Yamamoto N, Shiraki K. Seven cases of autoimmune hepatitis that developed after drug-induced liver injury. Hepatology 54: 1892-1893, 2011.

9. Whittaker SJ, Amar JN, Wanless IR, Heathcote J. Sulindac hepatotoxicity. Gut 23: 875-877, 1982.

10. van Haelst UJ, Sengers RC. Effects of parenteral nutrition with lipids on the human liver. An electron-microscopic study. Virchows Arch B Cell Pathol 22: 323-332, 1976.

11. Scheuer PJ. Acute viral hepatitis. In: Liver Biopsy Interpretation. Scheuer PJ, Lefkowitch JH, Eds. Saunders, London, 1994: 62-80.

12. Kozlov I, Beason K, Yu C, Hughson M. CD79a expression in acute myeloid leukemia $t(8 ; 21)$ and the importance of cytogenetics in the diagnosis of leukemias with immunophenotypic ambiguity. Cancer Genet Cytogenet 163: 62-67, 2005.

(C) 2016 The Japanese Society of Internal Medicine http://www.naika.or.jp/imonline/index.html 